\title{
Incidental Chest Radiographic Findings in Adult Patients With Acute Cough
}

Saskia van Vugt, $M D, M S c^{1}$

Lidewij Broekbuizen, $M D, P b D^{1}$

Nicolaas Zuithoff, MSc, $P b D^{1}$

Pim de Jong, $M D, P b D^{2}$

Christopher Butler, MD, $\mathrm{PbD}^{3}$

Kerenza Hood, $\mathrm{PbD}^{3}$

Samuel Coenen, $M D, P b D^{4}$

Herman Goossens, MD, $\mathrm{PbD}^{4}$

Paul Little, $M D, P b D^{5}$

Jordi Almirall, $M D, P b D^{6}$

Francesco Blasi, $M D, \mathrm{PbD}^{7}$

Slawomir Cblabicz, $M D, P b D^{8}$

Mel Davies, RN, $P b D^{9}$

Maciek Godycki-Cwirko, $M D, P b D^{10}$

Helena Hupkova, MD, PbD ${ }^{11}$

Janko Kersnik, $M D, P b D^{12}$

Artbur Mierzecki, $M D, P b D^{13}$

Sigvard Mölstad, $M D, P b D^{14}$

Michael Moore, $M D, P b D^{5}$

Tom Schaberg, $M D, P b D^{15}$

An De Sutter, MD, $P b D^{16}$

Antoni Torres, $M D, \mathrm{PbD}^{17}$

Pia Touboul, MD, PbD ${ }^{18}$

Theo Verbeij, $M D, P b D^{1}$

On behalf of the GRACE Project Group

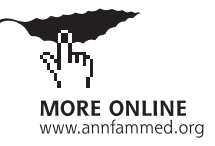

Conflicts of interest: authors report none.

\section{CORRESPONDING AUTHOR}

Saskia van Vugt, MD, MSc University Medical Centre Utrecht Julius Center for Health Sciences and Primary Care

Stratenum 5.149

PO Box 85500, NL- 3508 GA

Utrecht, the Netherlands

s.f.vanvugt@umcutrecht.nl

\begin{abstract}
PURPOSE Imaging may produce unexpected or incidental findings with consequences for patients and ordering of future investigations. Chest radiography in patients with acute cough is among the most common reasons for imaging in primary care, but data on associated incidental findings are lacking. We set out to describe the type and prevalence of incidental chest radiography findings in primary care patients with acute cough.

METHODS We report on data from a cross-sectional study in 16 European primary care networks on 3,105 patients with acute cough, all of whom were undergoing chest radiography as part of a research study workup. Apart from assessment for specified signs of pneumonia and acute bronchitis, local radiologists were asked to evaluate any additional finding on the radiographs. For the 2,823 participants with good-quality chest radiographs, these findings were categorized according to clinical relevance based on previous research evidence and analyzed for type and prevalence by network, sex, age, and smoking status.
\end{abstract}

RESULTS Incidental findings were reported in 19\% of all participants, and ranged from $0 \%$ to $25 \%$ by primary care network, with the network being an independent contributor $(P<.001)$. Of all participants 3\% had clinically relevant incidental findings. Suspected nodules and shadows were reported in $1.8 \%$. Incidental findings were more common is older participants and smokers $(P<.001)$.

CONCLUSIONS Clinically relevant incidental findings on chest radiographs in primary care adult patients with acute cough are uncommon, and prevalence varies by setting.

Ann Fam Med 2012;10:510-515. doi:10.1370/afm.1384.

\section{INTRODUCTION}

$\Lambda$ cute cough is one of the most common reasons for consulting in primary care. ${ }^{1,2}$ Prompt, accurate diagnosis of pneumonia in these patients is important to rule in the need for timely appropriate antibiotic treatment in some patients and to rule out the need for antibiotic treatment in others. Responsible general practitioners order chest radiographs in a minority of patients with acute cough. ${ }^{3}$ These radiographs confirm pneumonia in $5 \%$ to $19 \%$ and exclude pneumonia in most patients. ${ }^{2,4,5}$

Imaging provides information relevant to the acute illness but may also reveal incidental findings. ${ }^{6.9}$ Such findings can benefit patients through earlier diagnosis and treatment, for example, in as yet undiagnosed heart failure or malignancy. Incidental findings, however, may have unknown or doubtful clinical relevance and lead to patient anxiety, expensive workup, and potentially harmful investigations and treatment without improving quality and length of life..$^{10,11}$

The nature and prevalence of incidental findings on chest radiographs of patients who consult their general practitioner for acute cough is unknown. Such data may inform decisions about clinical indications for ordering chest radiographs. We studied incidental findings on chest radiographs obtained 
as part of an observational study in patients with acute cough in primary care in 12 European countries.

\section{METHODS}

We undertook a cross-sectional observational study using data from the GRACE-09/10a study (Genomics to combat Resistance against Antibiotics in Community-acquired lower respiratory tract infection [LRTI] in Europe; http://www.grace-lrti.org). ${ }^{12}$ The GRACE project contains an observational study (workpackage [WP] 9) with a trial randomizing patients with LRTI to amoxicillin or placebo (WP 10) nested within. The trial results will be reported separately. Data were collected in 16 primary care research networks in 12 European countries. Participating general practitioners recruited consecutive patients who were aged 18 years or older, complaining of acute cough (28 days or fewer duration) as the main symptom, and consulting their clinician for the first time for this illness episode. Further inclusion criteria were ability to fill out study materials and provide written informed consent. Exclusion criteria were pregnancy, lactation, and immunodeficiency. Medical ethics review committees in the participating countries approved the study.

\section{Outcome}

Chest radiographs were obtained for all patients, irrespective of clinicians' views, preferably within 3 days after study inclusion. Local radiologists assessed the 2-view radiographs and reported their findings and their suggested diagnosis on a standardized form. Provided diagnostic categories were normal chest radiograph, acute bronchitis, pneumonia, or other diagnosis (Supple-

\section{in} mental Appendix 1, available at http://annfammed. org/content/10/6/510/suppl/DC1). If a diagnosis of other was made, the radiologist was asked to specify this diagnosis. Radiologists were blinded to clinical data (signs, symptoms, and all other study results) but had access to previous radiographs of individual patients for comparison purposes. Radiologists informed the patient's general practitioner immediately if consolidation or any other diagnosis was identified that required further investigation. In all other cases, the clinicians received the results after the study had been completed.

A subset of 1,552 chest radiographs collected randomly from all participating primary care networks was reassessed independently by a single radiologist (P.J.) at the University Medical Center Utrecht to asses interobserver variability expressed by a $\kappa$ statistic. ${ }^{13}$ This radiologist was blinded to other patient characteristics and did not have access to previous images from patients. Of these 1,552 images, 398 (25\%) were singleview radiographs.

\section{Data Analysis}

All chest radiograph findings diagnosed as other were defined as incidental, and the prevalence and type were evaluated by sex, age, and smoking behavior, as these patient characteristics are most commonly related to prevalence of pulmonary disease. ${ }^{14-16}$ Differences in prevalence of incidental findings between primary care networks were quantified. The independent contribution of a network to the dichotomous diagnostic outcome (presence or absence of 1 or more incidental findings) was determined using multivariate regression analysis, including age, sex, and smoking behavior. All incidental findings were assessed from the radiographs in isolation from other patient data, including subsequent clinical course and outcome, and categorized according to their clinical relevance based on clinical consensus of the authors and recommendations from previous evidence (Supplemental Appendix 2, available at http:// annfammed.org/content/10/6/510/suppl/DC1).

\section{RESULTS}

\section{Patient Characteristics}

From 2007 to 2010, 294 general practitioners submitted data on 3,105 patients. Patients without a chest radiograph $(\mathrm{n}=259)$ or with a chest radiograph of insufficient quality for adequate interpretation $(n=23)$ were excluded (Figure 1). Patients without chest radio-

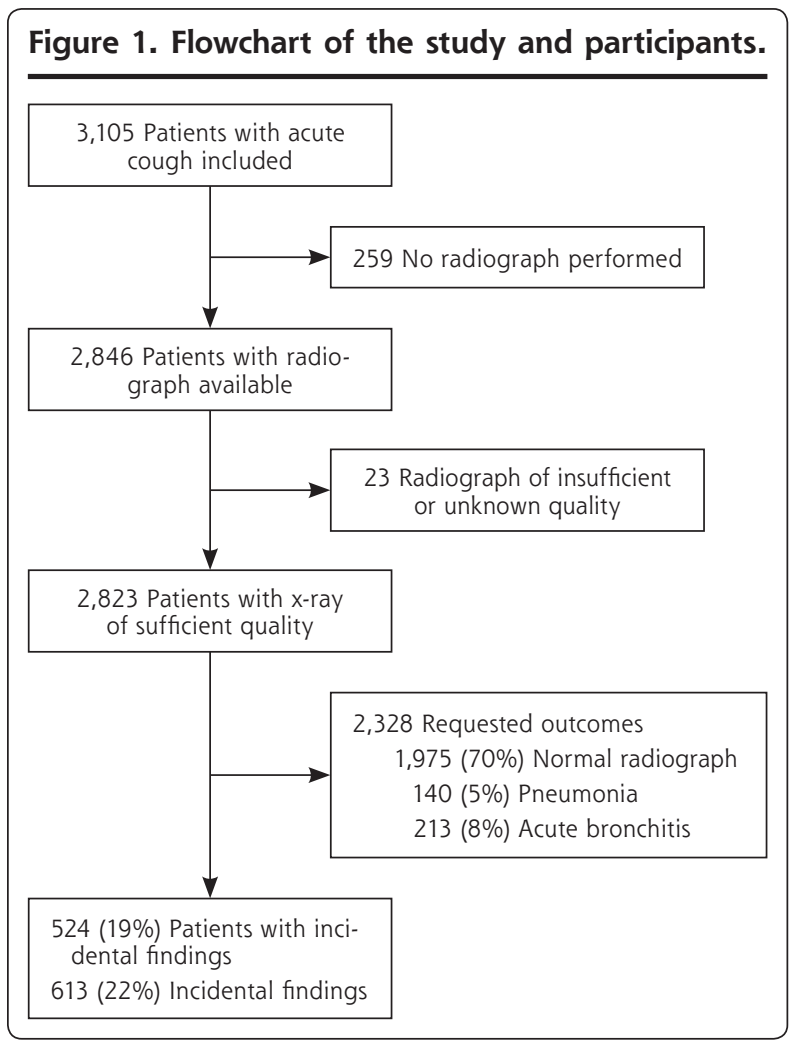


graph results were on average younger (mean age 44 years, range $=18-89$ years) than those with a chest radiograph result, but were otherwise similar in terms of baseline characteristics (data not shown). Patients' mean age was 50 years (range $=18-92$ years), and 1,131 (40\%) were men. Of all study patients 1,975 (70\%) had a normal chest radiograph; radiologists diagnosed pneumonia in 140 (5\%) of patients and acute bronchitis in $213(8 \%)$ of patients (Table 1). According to the reassessment of the independent radiologist, there was agreement regarding presence of pneumonia in $94 \%$, and weighted $\kappa=0.47$ (95\% confidence interval [CI], $0.38-0.56$; moderate agreement). The observed positive agreement $(50 \%)$ was much lower than for negative agreement (97\%).

\section{Prevalence of Incidental Findings by Primary Care Network}

There were 524 patients (19\%) with at least 1 incidental finding; more than 1 was reported for 63 patients, resulting in a total of 613 incidental findings. The frequency of reported diagnoses varied by network (Table 2 ), ranging from $0 \%$ in Jesenice (Slovenia) to 36\% in Lodz (Poland). The number of patients and their main characteristics by network are displayed in Table 2. Logistic regression analysis for the presence of any incidental finding, with age, sex, pack years of smoking, and network as independent variables, showed an independent contribution of network to the presence of incidental findings $(P<.001)$. According to the reassessment, there was agreement on the presence of incidental findings in $92 \%$, and weighted $\kappa=0.20$ (95\% CI, $0.14-0.26$; poor agreement). The observed positive agreement (13\%) was much lower than for negative agreement (96\%).

\section{Type of Incidental \\ Radiographic Findings}

Clinically relevant incidental findings were reported in $3.1 \%$ of all chest radiographs, of which $1.8 \%$ represented possible malignancy as the most common $(0.7 \%$ nodules, $0.7 \%$ densities, and $0.4 \%$ shadows). Findings associated with chronic pulmonary disease (eg, chronic obstructive pulmonary disease [COPD] and asthma) and cardiac conditions (eg, cardiomegaly or pulmonary congestion) were the most common probably relevant incidental findings (Table 3 ). Of these patients, $34 \%$ and $32 \%$ already (according to clinician data) had a diagnosis of pulmonary and cardiac disease, respectively.

\section{Associations Among Common Incidental Findings, Age, Sex, and Smoking}

Reports of hilar or mediastinal enlargement and signs suggesting COPD and asthma were almost twice as frequent in male patients. The prevalence of suspected nodules and shadows, signs of COPD and asthma, and cardiomegaly and pulmonary congestion increased with age. Among patients older than 75 years, 8.6\% were reported to have cardiomegaly or pulmonary congestion, and $14.1 \%$ were reported to have COPD or asthma. Incidental findings were more common in current or former smokers compared with never smok-
Table 1. Characteristics of 2,823 Primary Care Patients With Acute Cough by Radiographic Diagnosis

\begin{tabular}{lcccc}
\hline Characteristic & $\begin{array}{c}\text { Normal Chest } \\
\text { Radiograph }\end{array}$ & $\begin{array}{c}\text { Acute } \\
\text { Bronchitis }\end{array}$ & Pneumonia & $\begin{array}{c}\text { Incidental } \\
\text { Findings }\end{array}$ \\
\hline Patients, n (\%) & $1,975(70)$ & $213(8)$ & $140(5)$ & $524(19)$ \\
Age, mean (SD), y & $48(16)$ & $50(17)$ & $54(15)$ & $60(15)$ \\
Male, n (\%) & $742(38)$ & $96(45)$ & $62(44)$ & $231(47)$ \\
\hline
\end{tabular}

\section{Table 2. Main Characteristics of Patients per European Primary} Care Network

\begin{tabular}{lccccc}
\hline Network & $\begin{array}{c}\text { Patients } \\
\text { No. (\%) }\end{array}$ & $\begin{array}{c}\text { Age, y } \\
\text { Mean (SD) }\end{array}$ & $\begin{array}{c}\text { Male } \\
\text { No. (\%) }\end{array}$ & $\begin{array}{c}\text { Pack Years } \\
\text { Smoking, } \\
\text { Mean (SD) }\end{array}$ & $\begin{array}{c}\text { Incidental } \\
\text { Findings, } \\
\text { No. (\%) }\end{array}$ \\
\hline Antwerp & $277(10)$ & $49(17)$ & $126(46)$ & $10(16)$ & $80(29)$ \\
Barcelona & $300(11)$ & $55(18)$ & $97(32)$ & $10(17)$ & $67(22)$ \\
Bialystok & $134(5)$ & $36(12)$ & $64(48)$ & $3(7)$ & $11(8)$ \\
Bratislava & $147(5)$ & $44(13)$ & $64(44)$ & $3(6)$ & $9(6)$ \\
Cardiff & $250(9)$ & $53(17)$ & $108(43)$ & $15(23)$ & $60(26)$ \\
Ghent & $93(3)$ & $52(18)$ & $43(47)$ & $9(17)$ & $18(20)$ \\
Jesenice & $74(3)$ & $52(14)$ & $31(42)$ & $5(10)$ & $0(0)$ \\
Jonkoping & $98(4)$ & $55(16)$ & $34(35)$ & $7(12)$ & $7(7)$ \\
Lodz & $310(11)$ & $49(16)$ & $119(38)$ & $10(15)$ & $112(36)$ \\
Mataro & $286(10)$ & $49(18)$ & $137(48)$ & $10(18)$ & $18(6)$ \\
Milano & $77(3)$ & $53(15)$ & $34(44)$ & $10(17)$ & $7(9)$ \\
Nice & $29(1)$ & $54(17)$ & $9(31)$ & $3(5)$ & $1(3)$ \\
Rotenburg & $163(6)$ & $50(16)$ & $59(36)$ & $8(15)$ & $22(14)$ \\
Southampton & $203(7)$ & $51(16)$ & $62(31)$ & $6(12)$ & $47(23)$ \\
Szczecin & $107(4)$ & $47(15)$ & $28(26)$ & $9(14)$ & $2(2)$ \\
Utrecht & $273(10)$ & $53(15)$ & $113(41)$ & $10(18)$ & $30(19)$ \\
Total & $2,820(100)$ & $50(17)$ & $1,128(40)$ & $9(16)$ & $524(19)$ \\
\hline a Percentages are of & the total number & of patients in the network. & & \\
\hline
\end{tabular}


ers (Table 4). There was an independent association between pack years of smoking and the presence of incidental finding with an odds ratio of 1.02 (95\% CI, 1.01-1.03) per pack year.

\section{Table 3. Percentage of Incidental Radiographic Findings in Primary Care Patients With Acute Cough}

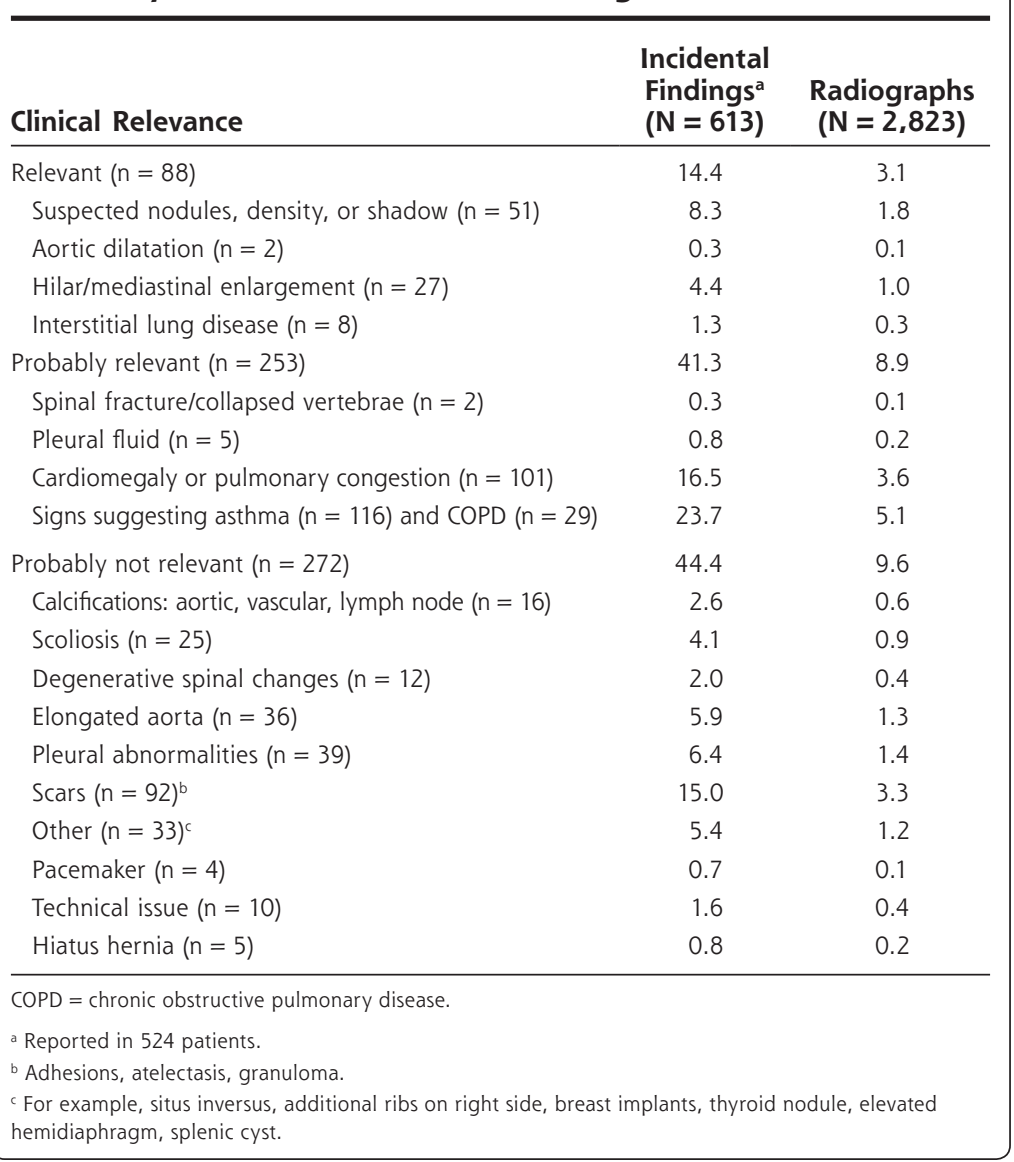

\section{DISCUSSION}

\section{Main Findings}

We found that $19 \%$ of 2,823 patients sequentially consulting their general practitioner for acute cough had incidental findings on the chest radiograph. This percentage varied by network, sex, age, and smoking status. Three percent of these patients had potentially clinically relevant incidental findings, including lung nodules and shadows.

\section{Strengths and Limitations}

This study is the first to describe incidental chest radiographic findings in patients with acute cough in primary care. We used the definition of incidental finding to include all reported findings apart from pneumonia and acute bronchitis. Some of these findings might have already been known to the treating general practitioner, for example, the presence of a pacemaker, and a diagnosis of asthma and COPD. In this study, however, all radiographic findings reported by the radiologist were taken into account, irrespective of the clinician's clinical record.

We based our definition of clinical relevance of incidental findings on our own clinical judgment and literature review. Although most clinicians will probably agree on which findings require further diagnostic workup (eg, suspected nodules, aortic dilatations,

Table 4. Most Frequently Reported (Potentially) Relevant Incidental Findings in Primary Care Patients With Acute Cough per Sex, Age-Group, and Smoking Behavior

\begin{tabular}{|c|c|c|c|c|c|c|c|c|c|}
\hline $\begin{array}{l}\text { Incidental } \\
\text { Finding }\end{array}$ & $\begin{array}{c}\text { Female } \\
n=1,692 \\
\text { No. }(\%)\end{array}$ & $\begin{array}{c}\text { Male } \\
\mathrm{n}=1,131 \\
\text { No. }(\%)\end{array}$ & $\begin{array}{c}P \\
\text { Value }^{a}\end{array}$ & $\begin{array}{c}\leq 50 y \\
n=1,388 \\
\text { No. }(\%)\end{array}$ & $\begin{array}{c}>50 y \\
n=1,435 \\
\text { No. }(\%)\end{array}$ & $\begin{array}{c}P \\
\text { Value }^{a}\end{array}$ & $\begin{array}{c}\text { Never } \\
\text { Smoked } \\
\mathrm{n}=1,295 \\
\text { No. }(\%)\end{array}$ & $\begin{array}{c}\text { Former } \\
\text { or Current } \\
\text { Smoker } \\
n=1523 \\
\text { No. }(\%)\end{array}$ & $\begin{array}{c}P \\
\text { Value }^{a}\end{array}$ \\
\hline $\begin{array}{l}\text { Any incidental } \\
\text { finding }\end{array}$ & $274(16.2)$ & $250(22.1)$ & $<.001$ & $123(8.9)$ & 401 (27.9) & $<.001$ & 207 (16.0) & $284(18.6$ & .044 \\
\hline $\begin{array}{l}\text { Suspected nodules, } \\
\text { density, or shadow }\end{array}$ & $32(1.9)$ & $19(1.7)$ & .68 & $16(1.2)$ & $35(2.4)$ & .010 & $24(1.8)$ & $23(1.5)$ & .27 \\
\hline $\begin{array}{l}\text { Hilar/mediastinal } \\
\text { enlargement }\end{array}$ & $6(0.4)$ & $21(1.9)$ & $<.001$ & $12(0.9)$ & $15(1.0)$ & .62 & $10(0.8)$ & $21(1.3)$ & .012 \\
\hline $\begin{array}{l}\text { Cardiomegaly or pul- } \\
\text { monary congestion }\end{array}$ & $62(3.7)$ & $38(3.4)$ & .67 & $17(1.2)$ & $83(5.8)$ & $<.001$ & $46(3.0)$ & $48(3.2)$ & .60 \\
\hline $\begin{array}{l}\text { Signs of COPD and } \\
\text { asthma }\end{array}$ & 61 (3.6) & $84(7.4)$ & $<.001$ & $30(2.2)$ & $115(8.0)$ & $<.001$ & $42(3.2)$ & $91(6.0)$ & $<.001$ \\
\hline
\end{tabular}


mediastinal enlargement, and interstitial lung disease), judgments of the clinical implications of other radiographic findings will vary by clinician and the clinician's patients. The evidence base supporting the definition of some radiological diagnoses is incomplete. For example, vascular redistribution and cardiomegaly were identified as radiological criteria for diagnosing cardiac failure in one study, ${ }_{1}^{17}$ whereas another study found no value of radiographic findings in diagnosing heart failure. ${ }^{18}$

Local radiologists in the centers associated with each primary care network examined chest radiographs. We aimed for uniform assessments through the use of a protocol for reporting abnormalities in the chest radiographs. Some interobserver variability remained, but the moderate agreement for pneumonia $(\kappa=0.47)$ was comparable to other studies. ${ }^{19-21}$ Interobserver variability on incidental findings $(\kappa=0.20)$ was much lower. The reporting protocol was less strictly defined for other findings compared with the protocol for pneumonia and acute bronchitis, suggesting that other mechanisms, including subjectivity between radiologists possibly related to training and experience, may have played a role. We were unable to quantify whether access to previous images for comparison purposes influenced reporting of incidental findings.

We did not follow up with study participants to determine clinical outcomes or the general practitioners' further management of the incidental findings, neither did we perform a reference standard test for all disorders that were suggested by the radiographic findings. As a result, our study does not allow an estimation of the (health) effects of reporting incidental findings in primary care patients with acute cough. Apart from such benefits as earlier diagnosis and treatment or prevention, ${ }^{8,22}$ there are several negative consequences that should be considered: radiation exposure, iatrogenic illness, patient inconvenience from additional testing, potentially unnecessary costs, and the psychological burden of false-positive results, as well as the detection of untreatable disease or diseases that might never have become symptomatic during life (overdiagnosis). ${ }^{10,11}$

Finally, patients volunteering to participate in an observational study may differ from the general population in primary care with acute cough. We did not gather data on eligible patients who were not included in the study and assume that many eligible patients were not recruited. The baseline characteristics of study participants, however, did not differ meaningfully from previous, similar studies, ${ }^{12}$ so risk from selection bias is probably low.

\section{Comparison With Other Studies}

One study found that $7.6 \%$ of patients had asthma for incidental findings on chest radiographs, compared with $19 \%$ of participants in our study with diagnosed asthma. ${ }^{9}$ Vertebral fracture proportions of $1.4 \%, 12.4 \%$, and $15.7 \%$ have been reported in studies on chest radiographs performed for any indication, ${ }^{6,7,23}$ which compares with $0.1 \%$ in our study population. The mean age of the patients in these previous 3 studies, however, was greater (older than 50, 67, and 75 years, respectively, compared with 50 years in our study). As adequate treatment of asymptomatic osteoporosis can prevent fractures and death, more active reporting of these fractures on chest radiographs might be warranted. Differences in mean age between our study participants and participants in other studies might also explain the increased frequency of cardiac abnormalities (eg, $4 \%$ and $6 \%), 9,24$ as well as the number of reported pulmonary abnormalities, eg, scars (14\%) and pleural abnormalities $(10 \%){ }_{1}^{24}$ in previous publications compared with those reported in our study.

\section{Clinical Implications}

We found large differences in prevalence of reported findings between primary care networks, which remained after adjustment for age, sex, and smoking status. These differences might be explained by differences in socioeconomic status, for which we had no data. Another explanation might be differences in professional routines, resulting in reporting differences. Uniformity in reporting could be improved through radiologist and referring clinicians agreeing on clinical relevance and need for reporting of incidental findings. Our results may inform decisions about the appropriate threshold for ordering chest radiographs in primary care, as well as in guiding clinicians in informing patients about the possibility of incidental findings when chest radiographs are ordered. We found few potentially clinically relevant incidental findings that would require additional investigations; therefore, there appears to be little reason for raising thresholds for requesting chest radiographs for acute cough because of fear of revealing incidental findings.

To read or post commentaries in response to this article, see it online at http://www.annfammed.org/content/10/6/510.

Key words: cough; lung/radiography; primary care; incidental findings

Submitted September 14, 2011; submitted, revised, December 23, 2011; accepted January 6, 2012.

Author affiliations: University Medical Center Utrecht, Julius Center for Health Sciences and Primary Care, Utrecht, the Netherlands (van Vugt, Broekhuizen, Zuithoff, Verheji); University Medical Center Utrecht, Department of Radiology, Utrecht, the Netherlands (de Jong); Cardiff University, Institute of Primary Care and Public Health, Cardiff, Wales (Butler); University of Antwerp, Laboratory of Medical Microbiology, Vaccine $\&$ Infectious Diseases Institute (VAXINFECTIO), Antwerp, Belgium (Coenen, Goossens); University of Southampton Medical School, 
Primary Care Medical Group, Southampton, United Kingdom (Little, Moore); Intensive Care Unit, Hospital de Mataro, Mataro, Spain (Almirall); Respiratory Medicine Section Dipartimento Toraco-Polmonare e Cardiocircolatorio, Università degli Studi di MilanoUniversity of Milan, IRCCS Fondazione Cà Granda Milano, Milan, Italy (Blasi); Department of Family Medicine and Community Nursing, Medical University of Bialystok, Bialystok, Poland (Chlabicz); Ely Bridge Surgery, Cardiff, United Kingdom (Davies); Department of Family and Community Medicine, Medical University of Lodz, Lodz, Poland (Godycki-Cwirko); Institute of Microbiology, Faculty of Medicine, Comenius University, Bratislava, Slovakia (Hupkova); Zdravstveni dom Jesenice, Jesenice, Slovenia (Kersnik); Independent Laboratory of Family Physician Education, Pomeranian Medical University, Szczecin, Poland (Mierzecki); Unit of Research and Development in Primary Care, Futurum, Jönköping, Sweden (Mölstad); Zentrum für Pheumologie, Diakoniekrankenhaus Rotenburg, Rotenburg, Germany (Schaberg); Ghent University, University Hospital, Ghent, Belgium (De Sutter); Pneumology Department, Clinic Institute of Thorax (ICT), Hospital Clinic of Barcelona- Insitut d'Investigacions Biomèdiques August Pi i Sunyer (IDIBAPS)- University of Barcelona (UB), Barcelona, Spain (Torres); Département de Santé Publique, Hôpital de I' Archet, Nice, France (Touboul).

Funding support: The design and conduct of the study, collection, management, analysis, and interpretation of the data and preparation, review, and approval of the study were all funded by 6th Framework Programme of the European Commission (Reference: LSHMCT-2005-518226). In Flanders (Belgium) this work was supported by the Research Foundation, Flanders (G.0274.08N).

Disclaimer: Funding sources were not involved in the design, conduct, analysis, and interpretation of the data, nor in the writing and decision to submit the paper. There was no pharmaceutical company involved. The corresponding author had full access to the data and had final responsibility for the decision to submit for publication.

Acknowledgments: We thank the entire GRACE team for their diligence, expertise, and enthusiasm. Finally, we are indebted to all patients who consented to be part of GRACE and their general practitioners, without whom this study would not have been possible.

\section{References}

1. Schappert SM, Burt CW. Ambulatory care visits to physician offices, hospital outpatient departments, and emergency departments: United States, 2001-02. Vital Health Stat 13. 2006;(159):1-66.

2. Macfarlane JF, Holmes WF, Gard PF, et al. Prospective study of the incidence, aetiology and outcome of adult lower respiratory tract illness in the community. Thorax. 2001;56(2):109-114.

3. Morice AH, McGarvey L, Pavord I, on behalf of the British Thoracic Society Cough Guideline Group. Recommendations for the management of cough in adults. Thorax. 2006;61(suppl_1):i1-24.

4. Hopstaken RM, Muris JW, Knottnerus JA, Kester AD, Rinkens PE, Dinant GJ. Contributions of symptoms, signs, erythrocyte sedimentation rate, and C-reactive protein to a diagnosis of pneumonia in acute lower respiratory tract infection. Br J Gen Pract. 2003;53(490): 358-364.

5. Woodhead MA FAU, farlane JT FAU, Cracken JS FAU, Rose DH FAU, Finch RG. Prospective study of the aetiology and outcome of pneumonia in the community. Lancet. 1987;1(8534):671-4.

6. Cataldi V, Laporta T, Sverzellati N, De Filippo M, Zompatori M. Detection of incidental vertebral fractures on routine lateral chest radiographs. Radiol Med. 2008;113(7):968-977.
7. Majumdar SR, Kim N, Colman I, et al. Incidental vertebral fractures discovered with chest radiography in the emergency department: prevalence, recognition, and osteoporosis management in a cohort of elderly patients. Arch Intern Med. 2005;165(8):905-909.

8. Orme NM, Fletcher JG, Siddiki HA, et al. Incidental findings in imaging research: evaluating incidence, benefit, and burden. Arch Intern Med. 2010;170(17):1525-1532.

9. Pickup CM, Nee PA, Randall PE. Radiographic features in 1016 adults admitted to hospital with acute asthma. J Accid Emerg Med. 1994;11(4):234-237.

10. Casarella WJ. A patient's viewpoint on a current controversy. Radiology. 2002;224(3):927.

11. Stone JH. Incidentalomas - clinical correlation and translational science required. N Engl J Med. 2006;354(26):2748-2749.

12. Butler $\mathrm{CC}$, Hood K, Verheij T, et al. Variation in antibiotic prescribing and its impact on recovery in patients with acute cough in primary care: prospective study in 13 countries. BMJ. 2009;338:b2242.

13. Cohen J. A coefficient of agreement for nominal scales. Educ Psychol Meas. 1960;20(1):37-46.

14. Rabe KF, Hurd S, Anzueto A, et al; Global Initiative for Chronic Obstructive Lung Disease. Global strategy for the diagnosis, management, and prevention of chronic obstructive pulmonary disease: GOLD executive summary. Am J Respir Crit Care Med. 2007;176(6): 532-555.

15. Depierre AF, Lagrange JL, Theobald S, et al; FNCLCC. Summary report of the Standards, Options and Recommendations for the management of patients with non-small-cell lung carcinoma (2000). Br J Cancer. 2003;89(Suppl 1):S35-S49.

16. Lindenfeld J, Albert NM, Boehmer JP, et al; Heart Failure Society of America. HFSA 2010 Comprehensive Heart Failure Practice Guideline. J Card Fail. 2010;16(6):e1-e194.

17. Badgett RG, Mulrow CD, Otto PM, Ramírez G. How well can the chest radiograph diagnose left ventricular dysfunction? J Gen Intern Med. 1996;11(10):625-634.

18. Nielsen OW, Hansen JF, Hilden J, Larsen CT, Svanegaard J. Risk assessment of left ventricular systolic dysfunction in primary care: cross sectional study evaluating a range of diagnostic tests. BMJ. 2000;320(7229):220-224.

19. Hopstaken RM, Witbraad T, van Engelshoven JM, Dinant GJ. Interobserver variation in the interpretation of chest radiographs for pneumonia in community-acquired lower respiratory tract infections. Clin Radiol. 2004;59(8):743-752.

20. Boersma WG, Daniels JM, Löwenberg A, Boeve WJ, van de Jagt EJ. Reliability of radiographic findings and the relation to etiologic agents in community-acquired pneumonia. Respir Med. 2006;100 (5):926-932.

21. Albaum MN, Hill LC, Murphy M, et al; PORT Investigators. Interobserver reliability of the chest radiograph in community-acquired pneumonia. Chest. 1996;110(2):343-350.

22. Gluecker TM, Johnson CD, Wilson LA, et al. Extracolonic findings at CT colonography: evaluation of prevalence and cost in a screening population. Gastroenterology. 2003;124(4):911-916.

23. Morris CA, Carrino JA, Lang P, Solomon DH. Incidental vertebral fractures on chest radiographs. Recognition, documentation, and treatment. J Gen Intern Med. 2006;21(4):352-356.

24. Wallace GM, Winter JH, Winter JE, Taylor A, Taylor TW, Cameron RC. Chest $X$-rays in COPD screening: are they worthwhile? Respir Med. 2009;103(12):1862-1865. 